\title{
Rural Women's Awareness about Breast Cancer in Southeastern Iran: a Cross-Sectional Study
}

\author{
Abbas Balouchi ${ }^{1}$, Hosien Shahdadi ${ }^{2}$, Esra AlKhasawneh ${ }^{3}$, Abdolghani \\ Abdollahimohammad ${ }^{2}$, Mohammadreza Firouzkouhi ${ }^{2}$, Hamed Sarani $^{4}$, Afsaneh \\ Gorgij $^{5}$
}

\begin{abstract}
Background: Breast cancer is the most common cancer among women worldwide. A very important factor in the timely treatment and prevention of progression is high breast cancer awareness. Rural women are at risk of latte stage breast cancer due to poor education and lack of access to medical facilities. Materials and Methods: This cross-sectional-descriptive study was conducted on 266 women (out of 300) aged over 18 in rural areas of Zabol, Southeastern Iran during July 2015 to October 2015. The data collection tool was a researcher-made questionnaire that measured participant knowledge of breast cancer in four aspects (general awareness, risk factors, mammography, and symptoms). SPSS 22 was used for statistical analysis. Results: Out of 266 participants, age information was available for 261 . The age range was between 19 and 62 , with a mean of $27 \pm 2.1$ years. Most participants $(154,57.9 \%)$ had an average overall awareness of breast cancer. In the general awareness dimension, most participants $(130,48.9 \%)$ had poor scores. Most $(166,62.4 \%)$ also had average awareness about risk factors and many $(137,51.5 \%)$ had good awareness about mammography. Most participants did not know that changes in breast shape $(232,88.2 \%)$, dimpling of breast skin $(192,72.3 \%)$ and nipple discharge $(183,69.6 \%)$ are the main symptoms of breast cancer. ANOVA statistical analysis showed a significant relationship between awareness level and participant education and occupation $(\mathbf{P}<0.05)$. Conclusions: This study indicated average awareness of participants about breast cancer. Since rural women have lower levels of education, it is recommended that educational courses with contents about breast cancer, its risk factors, and symptoms be held for these women.
\end{abstract}

Keywords: Awareness - rural women - breast cancer - risk factors - mammography - Iran

Asian Pac J Cancer Prev, 17 (4), 1875-1879

\section{Introduction}

Breast cancer is the most common cancer among women worldwide, especially in the developing countries (Jemal et al., 2010; Azeem et al., 2015; Siegel et al., 2015), so that most new cases of breast cancer and more than $62 \%$ of deaths from it occur in these countries(Poonawalla et al., 2013; Sankaranarayanan et al., 2013). A global report in 2010 indicated 13,835,000 cases of breast cancer and 458,400 deaths from breast cancer (Jemal et al., 2010; Celik et al., 2014). Breast cancer incidence rate has been rising in Iran in recent years (Harirchi et al., 2015). Breast cancer accounts for $24.4 \%$ of all malignancies in Iran, so that it is the most common malignancy among Iranian women. Its incidence is 36 cases per 100,000 people (Jazayeri et al., 2015). The main reason for this increase is the changes in lifestyle, obesity, chronic diseases, sedentary lifestyle, and family history (Majeed et al., 2014; Ebrahimi et al., 2015). Timely diagnosis of cancer in the early stages and proper medications increase the chances of recovery, increasing the lifetime of more than $90 \%$ of breast cancer patient (Abolfotouh et al., 2015).

There are many methods for detecting breast cancer including breast self-exam (BSE), which is easy to do, does not cost anything or require any equipment and trained personnel (Abdulkareem, 2014; Kataoka et al., 2015). The diagnostic power of BSE is $80-90 \%$ and can result in $50 \%$ reduction in mortality(Shiraly et al., 2010). Detecting the early signs of breast cancer in the early stages plays a key role in its early diagnosis and appropriate treatment so that if women do regular monthly

${ }^{1}$ Department of Nursing, Nursing and Midwifery School, Zabol University of Medical Sciences, ${ }^{2}$ Health Promotion Research Center, Zahedan University of Medical Sciences, Zahedan, Iran*For correspondence: hosienshahdadi@gmail.com 
breast exams, progress of $95 \%$ of cases of breast cancer to advanced stages can be prevented (Kwok et al., 2015). In addition, early diagnosis can prevent additional costs related to chemotherapy in late stages of the disease and improves patients' quality of life (Heidari et al., 2008; Abu-Helalah et al., 2014).

Promotion of women's awareness about breast cancer and its symptoms can encourage them to perform better and timelier breast self-exams. Several studies suggest lower rates of breast self-exam and low awareness about symptoms of breast cancer in Iran (Haji et al., 2002; Parsa and Kandiah, 2005; Montazeri et al., 2008; Charkazi et al., 2013). Rastad et al. reported that more than $50 \%$ of women had poor awareness about breast cancer (Rastad et al., 2013). Tilaki et al. showed that only $33.8 \%$ of women had good awareness about BSE and breast cancer risk factors (Tilaki and Auladi, 2015). Rural women's awareness about breast cancer is significantly lower than urban women due to lower literacy levels, lack of BSE-related trainings and lack of medical facilities (Kratzke et al., 2013; Mena et al., 2014). Lower awareness about breast cancer in rural women reduces their chance of detecting breast cancer symptoms, causing the breast cancer be detected at an advanced stage (stage III and IV) (Naghibi et al., 2013). Few studies have been conducted on Iranian rural women, especially in the studied area which is far from the capital. Considering low education levels of these women and given the importance of raising awareness about mammography and the risk factors affecting breast cancer and the preventability of breast cancer in the early stages, this study aimed at examining rural women's awareness about breast cancer in Southeastern Iran.

\section{Materials and Methods}

\section{Design and participants}

This cross-sectional-descriptive study was conducted on 266 women (out of 300) over 18 in rural areas of Zabol during July 2015 to October 2015. Zabol is a city located in Sistan and Baluchestan Province in Eastern Iran. Inclusion criteria were the age of over 18 years and willingness to complete the questionnaire.

\section{Data collection}

Simple random sampling was used for data collection. The questionnaires were distributed among rural women over 18. Each participant had 15 minutes to complete the questionnaire. Illiterate participants were interviewed, and their questionnaires were completed by the researcher. Questionnaires were then collected. Data collection tool was a researcher-made questionnaire. Previous studies in this field were used to design the questionnaire (Montazeri et al., 2008; Akhigbe and Omuemu, 2009; Tazhibi and Feizi, 2014). The questionnaire included 24 items and was composed of two parts. The first part evaluated the demographic characteristics in 3 items including age (20-29, 30-39, 40-49, 50-59, and more than 60 years), occupation (housewife, employee), and education (illiterate, elementary school, secondary school, high school diploma, associate degree, bachelor's degree and above). The second part measured the awareness levels and included 21 items in four areas of general awareness about cancer ( 3 items), awareness about breast cancer risk factors ( 8 items), Awareness about mammography (7 items), and awareness about breast cancer symptoms (6 items). Correct answers were scored one, and wrong answers were scored zero. The general awareness scores ranged from 0 to 21 . Scores of 0 to 7 indicated poor awareness, scores of 8 to 14 indicated average awareness , and scores of 15 to 21 indicated good awareness about breast cancer. Different dimensions of awareness were scored as follows. The total score of general awareness ranged from 0 to 3 . Scores of 0 to 1 indicated poor awareness, scores of 1 to 2 indicated average awareness, and scores of 2 to 3 indicated good awareness. The score of breast cancer risk factors ranged from 0 to 8 , where scores of 0 to 3 indicated poor awareness, scores of 3 to 6 indicated average awareness, and scores of 6 to 8 indicated good awareness. In the mammography dimension, the total score ranged from 0 to 7 , where scores of 0 to 3 indicated poor awareness, scores of 3 to 5 indicated average awareness, and scores of 5 to 7 indicated good awareness. Regarding awareness about symptoms of breast cancer, the total score ranged from 0 to 6 , where scores of 0 to 2 indicated poor awareness, scores of 2 to 4 indicated average awareness, and scores of 4 to 6 indicated good awareness. To confirm the validity and reliability of the questionnaire, it was presented to 10 breast cancer specialists, and its reliability was confirmed by Cronbach's alpha of 0.95 . This study was approved by the Ethics Committee of Zabol University of Medical Sciences. Oral and written informed consents were obtained from all participants. Participants were able to quit the study whenever they wanted.

\section{Data analysis}

Descriptive statistics (mean, frequency, frequency percentage) were used to determine the frequency of demographic characteristics and the level of women's awareness about breast cancer. Chi-square test was used to examine the relationship between awareness and demographic characteristics. SPSS V22 was used for data analysis. $\mathrm{p}<0.05$ was considered significant.

\section{Results}

\section{Demographic characteristics of participants}

Two-hundred sixty-six questionnaires (out of 300 questionnaires) were completed and returned by the participants. Response rate was $88.6 \%$.Out of 266 participants, age information was available for 261 . The age range of participants was 19-62 years. Mean age of participants was $27 \pm 2.1$. More than $83.8 \%$ of participants were housewives. Regarding education, $26.8 \%$ of participants were illiterate, $19.9 \%$ had elementary school education, $18.4 \%$ had middle school education, $19.2 \%$ had a high school diploma, 5.7\% had associate degree, and $10 \%$ had a bachelor degree or higher. Demographic characteristics are listed in Table 1.

Participants' awareness about breast cancer

Twenty-four items evaluated the awareness of 
Rural Women's Awareness about Breast Cancer in Southeastern Iran: a Cross-Sectional Study

participants about general awareness, breast cancer, risk factors, mammography, and breast cancer symptoms. Most participants $(154,57.9 \%)$ had average awareness about breast cancer. In the general awareness dimension, most participants $(130,48.9 \%)$ had poor general awareness about breast cancer (Table 2), $71.8 \%$ of participants believed that only females are affected by breast cancer (Table 3). Most participants $(166,62.4 \%)$ had average

Table 1. Socio-demographic Characteristics of Study Participants

\begin{tabular}{lcc}
\hline Age distribution $(\mathrm{n}=261)$ & Number & Percentage \\
\hline $18-29$ & 108 & 41.4 \\
$30-39$ & 94 & 36 \\
$40-49$ & 38 & 14.6 \\
$50-59$ & 9 & 3.4 \\
more than 60 & 12 & 4.6 \\
Occupation (n=260) & & \\
House wife & 218 & 83.8 \\
Employ & 42 & 16.2 \\
Education (n=261) & & \\
Illiterate & 70 & 26.8 \\
Elementary school & 52 & 19.9 \\
Middle school & 48 & 18.4 \\
high school diploma & 50 & 19.2 \\
Associate degree & 15 & 5.7 \\
Bachelor and higher & 26 & 10 \\
\hline
\end{tabular}

Awareness about breast cancer risk factors(Table 2).

Most participants believed that Use of oral contraceptive $(138,52.3 \%)$, old age $(153,57.5 \%)$, and menarche at age less than $12(207,79 \%)$ are the most important risk factors of breast cancer (Table 3). Most participants $(137,51.5 \%)$ had good awareness about

Table 2. Awareness of Rural Woman about Breast Cancer

\begin{tabular}{lcccc}
\hline \multicolumn{1}{c}{ Variable } & Level & $\begin{array}{c}\text { Frequency } \\
\text { (no.) }\end{array}$ & $\begin{array}{c}\text { Percent } \\
(\%)\end{array}$ & $\begin{array}{c}\text { Mean } \pm \\
\text { SD }\end{array}$ \\
\hline General & Poor & 130 & 48.9 & \\
Awareness & Average & 99 & 37.2 & $1.5 \pm 0.9$ \\
about cancer & Good & 37 & 13.9 & \\
awareness & Poor & 80 & 30.1 & \\
about breast & Average & 166 & 62.4 & $4.4 \pm 1.5$ \\
cancer risk & Good & 20 & 7.5 & \\
factors & Poor & 104 & 39.1 & \\
Awareness & Average & 25 & 9.4 & $4.8 \pm 2.7$ \\
about & Good & 137 & 51.5 & \\
mammography & Poor & 194 & 72.9 & \\
awareness & Average & 58 & 21.8 & $1.5 \pm 1.4$ \\
about breast & Good & 14 & 5.3 & \\
cancer & Poor & 15 & 5.6 & \\
symptoms & Average & 154 & 57.9 & $12.2 \pm 3.8$ \\
Overall & Good & 97 & 36.6 & \\
Awareness & & & & \\
\hline
\end{tabular}

Table 3. Frequency And Percentage Of Respondent's Answers About Different Domains 0f Awareness about Breast Cancer

\begin{tabular}{|c|c|c|}
\hline \multirow{2}{*}{ General Awareness about cancer } & Yes & No \\
\hline & $\mathrm{N}(\%)$ & $\mathrm{N}(\%)$ \\
\hline Only females are affected by breast cancer $(n=265)$ & $74(27.8)$ & $191(71.8)$ \\
\hline Breast cancer can be transmitted from one person to another. $(n=266)$ & $191(71.8)$ & $75(28.2)$ \\
\hline Breast cancer is the leading cause of death in Malaysian women. $(n=266)$ & $148(55.6)$ & $118(44.4)$ \\
\hline \multirow{2}{*}{ Awareness about breast cancer risk factors } & Yes & No \\
\hline & $\mathrm{N}(\%)$ & $\mathrm{N}(\%)$ \\
\hline Family history of breast cancer( $n=264)$ & $94(35.6)$ & $170(64.4)$ \\
\hline Use of oral contraceptive $(n=264)$ & $138(52.3)$ & $126(47.7)$ \\
\hline Old age $(n=262)$ & $153(57.5)$ & $109(41)$ \\
\hline $\operatorname{Obesity}(n=263)$ & $108(40.6)$ & $155(58.3)$ \\
\hline Cigarette smoking $(n=263)$ & $49(18.6)$ & $214(81.4)$ \\
\hline Low fat $\operatorname{diet}(n=262)$ & $235(89.7)$ & $27(10.3)$ \\
\hline Breastfeeding $(n=263)$ & $179(68.1)$ & $84(31.9)$ \\
\hline menarche at age less than 12 years $(n=262)$ & $207(79)$ & $55(21)$ \\
\hline \multirow{2}{*}{ Awareness about mammography } & Correct & Incorrect \\
\hline & $\mathrm{N}(\%)$ & $\mathrm{N}(\%)$ \\
\hline What is mammography? $(\mathrm{n}=252)$ & $170(67.5)$ & $82(32.5)$ \\
\hline How often should it be done? $(n=253)$ & $159(62.8)$ & $94(37.2)$ \\
\hline What is its benefit? $(\mathrm{n}=253)$ & $150(59.3)$ & $103(40.7)$ \\
\hline Is mammography painful? $(\mathrm{n}=254)$ & $189(74.4)$ & $65(25.6)$ \\
\hline Is mammography safe $?(n=253)$ & $185(73.1)$ & $68(26.9)$ \\
\hline Can it detect early stage breast cancer before it is palpable? $(n=252)$ & $161(63.9)$ & $91(36.1)$ \\
\hline Is mammography more beneficial in women $\geq 50$ years than those $<50$ years? $(n=250)$ & $181(72.4)$ & $69(27.6)$ \\
\hline \multirow{2}{*}{ Awareness about breast cancer symptoms } & Yes & No \\
\hline & $\mathrm{N}(\%)$ & $\mathrm{N}(\%)$ \\
\hline Painless breast lump(n=263) & $68(25.9)$ & $195(74.1)$ \\
\hline Lump under armpit(n=263) & $113(43)$ & $150(57)$ \\
\hline Nipple discharge $(n=263)$ & $80(30.4)$ & $183(69.6)$ \\
\hline Change in breast shape $(n=263)$ & $31(11.8)$ & $232(88.2)$ \\
\hline Pain in breast region $(n=262)$ & $48(18.3)$ & $214(81.7)$ \\
\hline Dimpling of breast skin( $n=262)$ & $70(26.7)$ & $192(72.3)$ \\
\hline
\end{tabular}


mammography (Table 2), most of the participants believed mammography is painless $(189,74.4 \%)$ and safe $(185$, $73.1 \%$ ), while 181 participants $(72.4 \%)$ believed that mammography at age less than 50 is more useful than the age of 50 (Table 3). Most participants (194, 72.9\%) had poor awareness about breast cancer symptoms (Table 2). Most participants did not know that the changes in breast shape $(232,88.2 \%)$, Dimpling of breast skin $(192,72.3 \%)$ and nipple discharge $(183,69.6 \%)$ are the main symptoms of breast cancer (Table 3).

ANOVA statistical analysis showed a significant relationship between the awareness and participants' education and occupation $(\mathrm{p}<0.05)$.

\section{Discussion}

Awareness of rural women about breast cancer was investigated in this study. Results showed that most participants had moderate awareness about breast cancer. Contrary to Rastad's study on women in Fasa (Southwestern Iran), results showed that most women (55\%) had poor awareness about breast cancer (Rastad et al., 2013). This difference can be attributed to the differences in study population. The results of the study by Muhammad A et al. (2010) showed that most women $(60.7 \%)$ had poor awareness about breast cancer in Malaysia (Hadi et al., 2010). The study conducted by Tiba Nezar Hasan in Iraq indicated low awareness (61.2\%) of most of the participants (Hasan et al., 2015). However, the study conducted by Gagdil et al. on women in Mumbai showed that most women had good awareness about breast cancer (Gadgil et al., 2014). The difference may be due to the fact that formal trainings about breast cancer are more efficient in India.

General awareness of women about breast cancer was moderate similar to Muhammad A's study in Malaysia; most participants believed that breast cancer is transmitted from one person to another, but in the study by Muhammad A et al., most participants believed that only women are at risk of breast cancer (Hadi et al., 2010). Most participants had moderate awareness about sub-factors, so that the participants believed that the following are the breast cancer sub-factors: low-fat diet $(89.7 \%)$, menarche at the age of fewer than 12 , and lactation $(68.1 \%)$. While in the study by Muhammad A, participants believed that cancer risk factors include: family history of breast cancer $(91.5 \%)$, smoking $(82.5 \%)$, and old age $(72.5 \%)$ (Hadi et al., 2010). In the study by Adenike $\mathrm{O}$ et al., the most important risk factors from the participants' perspective were family history $(92.2 \%)$, oral contraceptives $(82.4 \%)$ and old age (38.2\%) (Akhigbe and Omuemu, 2009). In the study by AM Ryan et al., the most important risk factors from the participants' perspective included smoking $(87 \%)$, diet $(76 \%)$, genetic $(47 \%)$ and alcohol consumption (42\%) (Ryan et al., 2015). In the study by LY Liu et al., the most important risk factors were menarche before age $12(11.2 \%)$, late menopause (13.7\%) and highfat diet (19.1\%) (Liu et al., 2014).

Most participants (51.5\%) had good Awareness about mammography, and 170 participants $(67.5 \%)$ knew the correct definition of mammography, while in the study by
Adenike O et al., 237 participants (60.3\%) knew the correct definition of mammography (22). Of the participants, 150 $(59.3 \%)$ knew the benefits of mammography testing, and $74.4 \%, 73.1 \%$ and $72.4 \%$ of participants believed mammography is painless, safe and useful in people over 50 compared to those less than 50 , respectively. While in the study by Adenike O et al., 61.6\%, 58\%, $19.8 \%$ of participants believed mammography is painless and safe and useful in people over 50 compared to those less than 50, respectively (Akhigbe and Omuemu, 2009). Most participants $(72.9 \%)$ had little awareness about the symptoms of cancer. The most important symptoms of breast cancer from the women's views were as follows: axillary mass $(113,43 \%)$, nipple discharge $(80,30.4 \%)$ and dimple in the breast skin $(70,26.7 \%)$, while in the study by Muhammad A et al., the most important symptoms of breast cancer from the perspective of women included change the angle of the breast $(81.5 \%)$, axillary mass and breast pain $(78.5 \%$ ) (Hadi et al., 2010). Montazeri et al. reported that the most important symptoms of breast cancer from women's perspective were axillary mass $(44 \%)$, painful axillary mass $(16 \%)$ and changes in breast shape (13\%) (Montazeri et al., 2008).

This study had some limitations that should be noted. This was a descriptive study, in which the self-report questionnaires were completed quickly with yes or no responses. The questionnaire included only the most important risk factors and symptoms of breast cancer not and all the risk factors and symptoms associated with breast cancer.

In conclusion, This study indicated a moderate awareness about breast cancer. Breast cancer is the most common cancer in women, and since rural women had lower literacy levels, training courses on breast cancer, its risk factors, and symptoms are recommended to be held for these women.

\section{References}

Abdulkareem ST (2014). Breast magnetic resonance imaging indications in current practice. Asian Pac J Cancer Prev, $15,569$.

Abolfotouh MA, Ala'a AB, Mahfouz AA, et al (2015). Using the health belief model to predict breast self examination among Saudi women. BMC Public Health, 15, 1.

Abu-Helalah M, Al-Hanaqta M, Alshraideh H, et al (2014). Quality of life and psychological well-being of breast cancer survivors in Jordan. Asian Pac J Cancer Prev, 15, 5927-36.

Akhigbe AO, Omuemu VO (2009). Knowledge, attitudes and practice of breast cancer screening among female health workers in a Nigerian urban city. BMC Cancer, 9, 1.

Azeem E, Gillani SW, Siddiqui A, et al (2015). Knowledge, Attitude and Behavior of Healthcare Providers towards Breast Cancer in Malaysia: a Systematic Review. Asian Pac J Cancer Prev, 16, 5233-5.

Celik S, Tasdemir N, Sancak H, et al (2014). Breast cancer awareness among Turkish nursing students. Asian Pac J Cancer Prev, 15, 8941-6.

Charkazi A, Samimi A, Razzaghi K, et al (2013). Adherence to recommended breast cancer screening in Iranian Turkmen women: the role of knowledge and beliefs. ISRN Prev Med, 2013, 1-8.

Ebrahimi M, Vahdaninia M, Montazeri A (2015). Risk factors 
for breast cancer in Iran: a case-control study. Breast Cancer Res, 4,4 .

Gadgil A, Sauvaget C, Roy N, et al (2014). Breast cancer awareness among middle class urban women-a communitybased study from mumbai, India. Asian Pac J Cancer Prev, 16, 6249-54.

Hadi MA, Hassali MA, Shafie AA, et al (2010). Evaluation of breast cancer awareness among female university students in Malaysia. Pharmacy Practice, 8, 29-34.

Haji-Mahmoodi M, Montazeri A, Jarvandi S, et al (2002). Breast self-examination: knowledge, attitudes, and practices among female health care workers in tehran, Iran. Breast J, 8, 222-5.

Harirchi I, Karbakhsh M, Hadi F, et al (2015). Patient delay, diagnosis delay and treatment delay for breast cancer: comparison of the pattern between patients in public and private health sectors. Archives Breast Cancer, 2, 52-7.

Hasan TN, Shah SA, Hassan MR, et al (2015). Poor knowledge and practice towards breast cancer among women in Baghdad City, Iraq. Asian Pac J Cancer Prev, 16, 6669-72.

Heidari Z, Mahmoudzadeh-Sagheb H, Sakhavar N (2008). Breast cancer screening knowledge and practice among women in southeast of Iran.

Jazayeri SB, Saadat S, Ramezani R, et al (2015). Incidence of primary breast cancer in Iran: Ten-year national cancer registry data report. Cancer Epidemiol, 39, 519-27.

Jemal A, Center MM, DeSantis C, et al (2010). Global patterns of cancer incidence and mortality rates and trends. Cancer Epidemiol Biomarkers Prev, 19, 1893-907.

Kataoka Y, Ohbayashi K, Suzuki K (2015). Outcome evaluation of an educational program for Japanese midwives to promote breast awareness for women. Women Birth, 28, 164-70.

Kratzke C, Wilson S, Vilchis H (2013). Reaching rural women: Breast cancer prevention information seeking behaviors and interest in Internet, cell phone, and text use. J Community Health, 38, 54-61.

Kwok C, Tranberg R, Lee F (2015). Breast cancer knowledge, attitudes and screening behaviors among Indian-Australian women. European J Oncol Nurs, 19, 701-6.

Liu L-Y, Wang F, Yu L-X, et al (2014). Breast cancer awareness among women in Eastern China: a cross-sectional study. BMC Public Health, 14, 1.

Majeed W, Aslam B, Javed I, et al (2014). Breast cancer: major risk factors and recent developments in treatment. Asian Pac J Cancer Prev, 15, 3353-8.

Mena M, Wiafe-Addai B, Sauvaget C, et al (2014). Evaluation of the impact of a breast cancer awareness program in rural Ghana: A cross-sectional survey. Int J Cancer, 134, 913-24.

Montazeri A, Vahdaninia M, Harirchi I, et al (2008). Breast cancer in Iran: need for greater women awareness of warning signs and effective screening methods. Asia Pac Family Med, 7,1 .

Naghibi A, Shojaeezade D, Montazeri A (2013). Early detection of breast cancer among women in Mazandaran, Iran.

Parsa P, Kandiah M (2005). Breast cancer knowledge, perception and breast self-examination practices among Iranian women. Int Med J, 4, 17-24.

Poonawalla IB, Goyal S, Mehrotra N, et al (2013). Attitudes of South Asian women to breast health and breast cancer screening: findings from a community based sample in the United States. Asian Pac J Cancer Prev, 15, 8719-24.

Rastad H, Shokohi L, Dehghani SL, et al (2013). Assessment of the Awareness and Practice of Women vis-à-vis Breast Self-Examination in Fasa in 2011. J Fasa University Med Sci, 3, 75-80.

Ryan AM, Cushen S, Schellekens H, et al (2015). Poor awareness of risk factors for cancer in irish adults: results of a large survey and review of the literature. Oncologist, 20.
Sankaranarayanan R, Alwan N, Denny L (2013). How can we improve survival from breast cancer in developing countries? Breast Cancer Management, 2, 179-83.

Shiraly R, Asadollahi K, Asadollahi P (2010). Risk perception and preventive issues for breast cancer among female employees. Iranian J Cancer Prev, 3, 166-73.

Siegel RL, Miller KD, Jemal A (2015). Cancer statistics, 2015. CA Cancer J Clin, 65, 5-29.

Tazhibi M, Feizi A (2014). Awareness levels about breast cancer risk factors, early warning signs, and screening and therapeutic approaches among Iranian adult women: a large population based study using latent class analysis. Bio Med research international, 2014.

Tilaki KH, Auladi S (2015). Awareness, attitude, and practice of breast cancer screening women, and the associated sociodemographic characteristics, in Northern Iran. Iranian $J$ Cancer Prev, 8, 3429. 